\title{
Effects of Walking Type and Speed on Oxygen Uptake and Fat Oxidation in College Students
}

\author{
Hye-Yeong Kim ${ }^{1 *}$, Keun-Ok An ${ }^{1 *}$, Sung-Sik Ko ${ }^{1 * *}$ \\ ${ }^{1}$ Korea National University of Transportation, Chungju, Republic of Korea
}

Received: August 21, 2021

Accepted: October 5, 2021

Published online: January 31, 2022

Keywords:

Energy Expenditure

Fat Oxidation Rate

Oxygen Uptake

Walking Speed

Walking Type

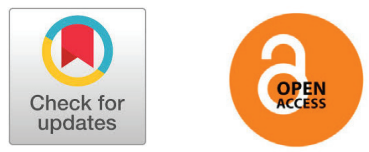

\section{ABSTRACT}

OBJECTIVES The purpose of this study was to investigate the difference in oxygen uptake, fat oxidation rate, and fat oxidation during treadmill walking, depending on the type and speed of walking.

METHODS Ten male college students randomly participated in the experiment under two conditions. Four types of exercise: normal walking, power walking, dumbbell walking, and sand walking, and three exercise intensity conditions: low-speed walking ( $40 \% \mathrm{VT})$, medium-speed walking ( $50 \% \mathrm{VT})$, and high-speed walking $(60 \%$ VT).

RESULTS Oxygen uptake was statistically significantly higher as walking speed increased $(p<.001)$, and there was no statistically significant difference in walking type, but the interaction effect was statistically significant $(p=.048)$. The fatty acid oxidation rate was statistically significantly lower as the walking speed increased $(p<.001)$, and there was no significant difference in walking type, but the interaction effect was statistically significant $(p=.008)$. There was a significant difference in the amount of fat burning according to the walking speed $(p=.007)$, but there was no difference in the walking type, and there was no interaction effect.

CONCLUSIONS Dumbbell walking and band walking increased oxygen intake under medium and high speed walking conditions, excluding low speed, compared to normal walking, and it is shown that normal walking and sand walking have an advantage in increasing the fat oxidation rate. In particular, considering the amount of fat oxidation, sand walking in all speed conditions is considered to be effective for weight loss, and it is suggested that it is necessary to investigate this later.

(c) The Asian Society of Kinesiology and the Korean Academy of Kinesiology

\section{서론}

걷기는 다른 유산소 운동유형에 비해 관절에 가해지 는 물리적 스트레스가 적고 안전한 운동으로 현대인들 의 건강유지와 증진을 위해 가장 널리 이용되고 있으며 [1], 지방을 감소시켜 비만자를 위한 운동에 적합하고, 심혈관계 기능향상, 혈압감소, 이상지질혈증 개선, 혈당 조절 개선 및 유방암과 직장암의 예방효과가 있다 $[2,3$, 4]. 하지만 걷기운동은 다른 유산소성 운동에 비해 상

* These two authors contributed equally to this work.

**Correspondence: Sung-Sik Ko, Sports Medicine Major, Division of Sports, Korea National University of Transportation, Chungju, Republic of Korea; Tel: +82-43-8415994; E-mail: koss@ut.ac.kr
대적으로 에너지소비량이 적기 때문에 동일한 운동효 과를 보기 위해서는 장시간 운동을 실시해야 하거나 상 대적으로 운동강도가 높지 않으므로 체력이 좋은 사람 들의 경우에는 걷기운동만으로 목표심박수에 도달하지 못하는 단점도 있다[5]. 이를 보완하기 위하여 걷기운 동 형태를 변화시켜서 운동의 효과를 높이고자 시도되 고 있다. 일반걷기는 특별한 장비나 비용 없이도 할 수 있는 운동유형이고, 파워걷기는 등을 곧게 펴고 발뒤꿈 치, 발바닥, 엄지발가락 순으로 중심 이동을 하며, 팔꿈 치관절을 90도 구부리고 팔을 힘차게 흔들며, 빠른 걷 기를 하는 운동을 말한다[1]. 덤벨들고 걷기는 적정무 
게의 덤벨을 손에 잡고 걷는 운동형태로 일반적인 걷기 운동 시 부족할 수 있는 상지부위의 운동을 보다 적극 적으로 보완하려는 목적에서 고안된 방법이다[6]. 모래 주머니차고 걷기는 발목에 모래주머니를 차고 짧은 시 간 걷기운동에서 운동량을 늘리기 위한 대안으로 제시 된 방법이다[7]. 이 외에도 노르딕걷기, 매트걷기, 모래 걷기 등이 실시되고 있다. 또한 걷기운동에서 보행의 강 도는 대사적인 반응으로 평가되며, 에너지소비는 보행 속도에 영향을 받게 된다[8]. 그러므로 보행속도는 운 동량에 직접적인 영향을 주며 운동의 효과를 결정짓는 주요 요인이다[9].

파워보행이 일반보행보다 더 많은 근육을 사용함으 로써 다리근육의 근력강화와 에너지소비에 더 효과적이 었다[10]. 남자 대학생을 대상으로 4가지 걷기운동을 실시하였을 때 덤벨들고 걷기 $(85.4 \mathrm{kcal} / \mathrm{min})$ 운동이 에 너지소비에 가장 효과적이었고 노르딕걷기 $(77.0 \mathrm{kcal} /$ $\min )$, 파워걷기 $(68.7 \mathrm{kcal} / \mathrm{min})$ 순으로 나타났다[11]. 그리고 노르딕걷기가 일반걷기보다 $20 \%$ 정도의 대사 적인 요구가 높다고 하였으며[12], 이와 비슷한 양상의 결과를 보고한 연구도 있다. [9, 13]. 또 다른 연구에서 는 남자 대학생들을 대상으로 걷기운동 시 중량부하물 을 착용하는 부위와 중량부하 차이에 따른 에너지대사 반응을 연구하였는데, 최소한의 운동효과를 얻기 위한 중량부하물의 무게는 체중의 $2 \%$ 이었고 착용부위는 몸 통보다는 손과 발목 부위에 부착하는 것이 더 효과적이 라고 하였다[14]. 남자 대학생들을 대상으로 발목에 모 래주머니를 차고한 걷기운동에서 체중의 약 $3 \%$ 에 해당 하는 중량을 부하할 때 에너지소비량이 더 증가하였다 [15]. 모래주머니차고 걷기가 일반걷기보다 충격량을 더 높이며 [16], 걷기운동에서 덤벨의 중량이 증가할수 록 심박수와 에너지소비가 증가하였다[17].

보행속도와 관련지어 볼 때, 보행속도가 높을수록 심박수와 에너지소비량이 높다고 주장한 반면에 [18], $6 \mathrm{~km} / \mathrm{h}$ 이하의 보행속도에서는 에너지소비량에 영향을 거의 미치지 않았으며, $7 \mathrm{~km} / \mathrm{h}$ 의 속도에서 현저한 영향 을 미쳤다고 하였다[15]. 다른 연구에서는 비만 남성들 에 게 걷기운동 속도를 다르게 하여 8주간 운동을 실시 한 결과 중간속도 $(5.5 \mathrm{~km} / \mathrm{h})$ 이상으로 걷기운동을 수행 하는 것이 신체구성을 개선시키는데 긍정적인 효과가 있 었으며[19], 6 7km/h의 보행속도에서 에너지소비량 이 가장 높았다[11]는 주장도 제기되고 있다.
이상에서 살펴본 바와 같이 여러 선행연구에서는 걷 기운동 유형과 중량부하 및 보행속도에서 따라서 나타 나는 걷기운동의 효과를 규명하는 것이 대부분이고, 주 로 동일한 보행속도 조건에서 적절한 중량부하를 찾거 나 혹은 효과적인 운동유형을 확인하는 등의 비교적 단 편적인 조건에서 걷기운동의 효과를 규명하는 것이 주 류를 이루고 있다. 이에 이 연구는 보행속도가 에너지소 비를 결정하는 주된 요인이므로[8], 상대적인 3가지 보 행속도 조건과 또한 가장 많이 사용하고 있는 4 가지 걷 기운동 유형을 동시에 고려하였을 때 나타나는 걷기운 동의 효과를 에너지대사 측면에서 확인하고자 하였다.

따라서 이 연구는 일반걷기, 파워걷기, 덤벨들고 걷 기, 모래주머니차고 걷기의 4 가지 운동유형과 환기역치 (ventilatiory threshold, VT) 수준에 근거한 저속걷기 (40\%VT), 중속걷기(50\%VT), 고속걷기(60\%VT)의 세 가지 보행속도 수준에서 트레드밀 걷기운동을 실시하였 을 때, 산소섭취량, 지방연소율 및 지방연소량의 차이를 알아보는데 목적을 두었다.

\section{연구방법}

\section{1. 연구대상}

$\mathrm{K}$ 대학교 남자 체육 전공자를 대상으로 실험의 목 적, 검사의 내용과 방법에 관한 자세한 내용을 공고를 통해 안내하였으며, 자발적으로 참여의사를 밝히고 참 가 동의서에 서명한 남학생 10 명을 선정하였다. 이들은 의학적으로 이상이 없고 건강하였으며 사전에 본 실험 에 대한 운동검사의 내용과 방법 및 피험자 숙지사항을 충분히 이해하고 참여하였다. 피험자들의 신체적 특성 은 <Table 1 >과 같다.

Table 1. Characteristics of the subjects

\begin{tabular}{ll}
\hline Age $(\mathrm{yr})$ & $20.1 \pm 0.3$ \\
Height(cm) & $176.3 \pm 5.4$ \\
Weight $(\mathrm{kg})$ & $67.0 \pm 6.3$ \\
$\mathrm{BMI}$ & $21.6 \pm 1.7$ \\
Body fat $(\%)$ & $16.2 \pm 3.1$ \\
$\mathrm{VO}_{2} \mathrm{max}(\mathrm{ml} / \mathrm{kg} / \mathrm{min})$ & $51.0 \pm 3.6$ \\
$\mathrm{VO}_{2} \mathrm{VT}(\mathrm{ml} / \mathrm{kg} / \mathrm{min})$ & $32.6 \pm 2.1(64 \%)$ \\
\hline
\end{tabular}

Values are expressed as mean \pm standard deviation. 


\section{2. 실험설계}

\section{1) 사전검사}

실험 전에 기본검사로서 신장과 체성분 검사(Inbody 4.0, Korea)를 실시한 다음 Bruce 프로토콜로 트레드 밀 최대운동부하검사를 실시하여 $\mathrm{VO}_{2} \max$ 를 측정하였 다. $\mathrm{VO}_{2} \max$ 는 자동가스분석기(quark, USA)로 분석하 였으며 매회 피험자 측정 전에는 $16 \%$ 혼합가스(High $\mathrm{Cal}, \mathrm{O}_{2} 15 \%, \mathrm{CO}_{2} 5 \%$ )와 가스용적측정기(3L)를 이용 하여 영점조절을 하였다. $\mathrm{VO}_{2} \max$ 의 측정은 호흡교환 율이 1.15 이상이거나 운동강도가 증가함에도 불구하고 산소소비량이 고원을 이루거나, 심박수가 예측된 최대 심박수의 $90 \%$ 이상 도달되었거나 주관적 자각도(RPE) 가 17 이상일 경우, 혹은 피험자가 중지를 요구한 시점 중 두가지 이상을 만족했을 때의 $\mathrm{VO}_{2 \mathrm{PEAK}}$ 를 $\mathrm{VO}_{2} \max$ 로 결정하였다[20].

일반적으로 유산소성 운동에서의 운동강도는 $\% \mathrm{VO}_{2} \max$ 가 주로 사용되고 있지만 본 연구에서는 트 레드밀 걷기운동으로서 비교적 낮은 운동강도 이었으 므로 $\mathrm{VO}_{2} \max$ 를 기준으로 개별적인 걷기의 운동강도를 제시할 경우 $\% \mathrm{VO}_{2} \max$ 가 너무 낮아지게 된다. 따라서 개별화된 운동강도의 기준으로 무산소성 역치의 수준을 권고한 선행연구에 근거하여[21], 환기역치의 퍼센트 $(\% \mathrm{VT})$ 를 기준으로 걷기속도의 운동강도를 결정하였다.

환기역치 $(\mathrm{VT})$ 는 $\mathrm{VO}_{2}$ 의 비례적인 증가에 비해 $\mathrm{VCO}_{2}$ 가 비직선적으로 증가폭이 변곡되는 시점으로 결정하는 $\mathrm{V}$-slope 방법으로 결정하였다[22]. 또한 VT의 $40 \%$, $50 \%, 60 \%$ 에 해당하는 트레드밀 걷기속도는 아래의 공 식으로 결정하였으며, 이 때 경사도는 $3 \%$ 로 고정시켜 산출하였다.

$$
\begin{aligned}
\mathrm{VO}_{2}= & 3.5+\operatorname{speed}(\mathrm{m} / \mathrm{min}) \times 0.1+\operatorname{grade}(\%) \times \\
& \operatorname{speed}(\mathrm{m} / \mathrm{min}) \times 1.8
\end{aligned}
$$

\section{2) 실험방법 및 절차}

실험은 일반걷기, 덤벨을 이용한 걷기(덤벨들고 걷 기), 발목에 모래주머니 밴드를 이용한 걷기(모래주머 니차고 걷기) 및 파워걷기의 네 가지 걷기운동을 일주 일에 1 회씩 총 4 회의 실험을 진행하였다. 이때 걷는 순 서는 무선할당 방법에 의해 무작위로 진행하였고 각각 의 개인들은 동일한 시간대에 실험을 실시하였다. 일반 걷기는 자연스럽게 걷는 상태로 실시하였고, 덤벨들고
걷기는 상지에 $1 \mathrm{~kg}$ 의 덤벨을 양손에 각각 하나씩 들고 실시하였다. 밴드걷기는 하지에 $1 \mathrm{~kg}$ 의 모래주머니를 양 쪽 발목에 각각 착용한 후 걷기 운동을 실시하였고, 파 워걷기는 팔을 앞뒤로 90 도로 흔들면서 걷도록 하였다. 모든 실험은 식후 2 시간 이상 경과한 조건에서 실험실 에 도착하여 앉은 자세에서 30 분 정도 안정을 취한 후 에 실시하였다. 피험자들은 실험 전날 24시간 이상 과 도한 운동을 피하고 알코올 섭취를 제한하도록 하였으 며 충분한 수면을 취하도록 교육하였다.

매번 실험은 트레드밀에 $3 \%$ 의 경사도로 고정한 상 태에서 저속걷기(40\%VT), 중속걷기(50\%VT) 및 고속 걷기 $(60 \% \mathrm{VT})$ 의 걷기속도에서 각각 2 분씩 총 6 분간 준 비운동과 4 분간 휴식을 취하도록 하였다. 이후 $40 \% \mathrm{VT}$, $50 \% \mathrm{VT}$ 및 $60 \% \mathrm{VT}$ 의 조건에서 각각 10 분씩 30 분 동 안 걷기운동을 실시하였으며, 각각의 트레드밀 평균 속 도는 $3.7 \mathrm{~km} / \mathrm{h}, 5.0 \mathrm{~km} / \mathrm{h}$ 및 $6.2 \mathrm{~km} / \mathrm{h}$ 이었다. 걷기운동 프로토콜은 <Table 2>와 같다.

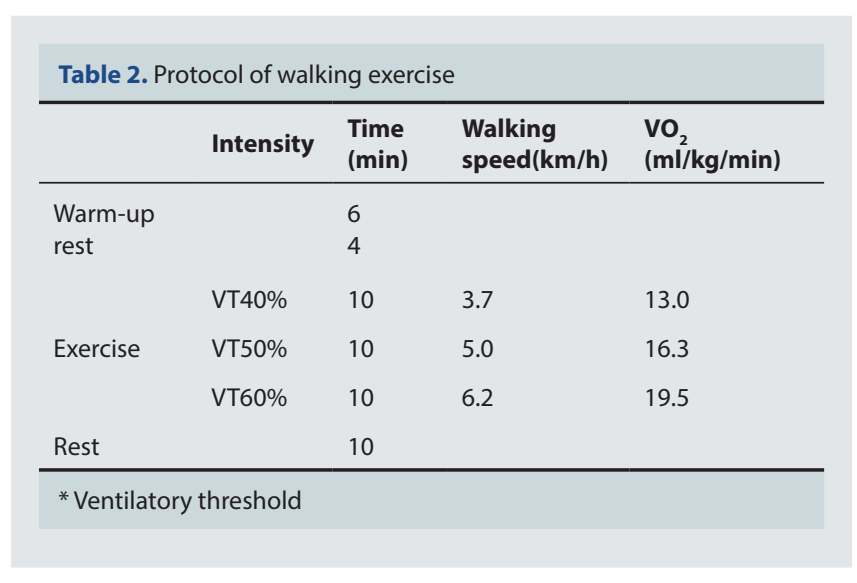

산소섭취량, 지방산화율 및 분당 지방연소량의 에너 지대사 변인은 각각 30 초 단위로 분석하여 10 분간의 평 균으로 산출하였고, 그 중 지방산화율과 분당 지방연소 량은 호흡교환율과 Lusk table[23]을 이용하여 분당산 소소비량을 분당 지방연소량으로 매 1 분 단위로 변환하 여 다음의 Frayn의 공식으로 산출하였다[24]. 걷기운 동을 마친 후에는 바로 의자에 앉아 10 분간 휴식을 취 하도록 하였다.

Fat oxidation $(\mathrm{mg} / \mathrm{min})=1.67 \times \mathrm{VO}_{2}(\mathrm{~mL} / \mathrm{min})-$

$$
1.67 \times \mathrm{VCO}_{2}(\mathrm{~mL} / \mathrm{min})
$$




\section{3. 자료처리}

본 연구의 자료는 SPSS(Ver.20.0) 통계프로그램 을 이용하여 분석하였다. 걷기유형(4)과 걷기속도(3) 에 따른 에너지대사 변인들의 차이를 검증하기 위하여 반복측정 two-way ANOVA로 분석하였고, 사후비교 (contrast)를 위해 simple(first)와 repeated 방법을 적 용하였다. 통계학적 유의수준은 $a=.05$ 로 결정하였다.

\section{연구 결과}

걷기유형과 걷기속도에 따른 산소섭취량, 지방산화 율 및 지방연소량은 <Table 3>에 제시한 바와 같다.

산소섭취량은 걷기속도에 따라 유의한 차이가 나타 났으나 $(\mathrm{p}<.001)$ 걷기유형에서는 유의한 차이를 보이지 않았다. 반면 걷기속도와 걷기유형 간에 상호작용효과 는 유의하였다 $(\mathrm{p}=.048)$. 사후비교 결과 산소소비량은 고속걷기, 중속걷기, 저속걷기 순으로 높게 나타났다. 또한 중속걷기에서는 일반걷기보다 파워걷기, 덤벨들 고 걷기, 모래주머니차고 걷기 순으로, 고속걷기에서는 일반걷기와 파워걷기보다는 덤벨들고 걷기, 모래주머 니차고 걷기 순으로 산소섭취량이 유의하게 증가하는 양상을 나타냈다.
지방산화율은 걷기속도에 따라 유의한 차이가 나타 났으나 $(\mathrm{p}<.001)$ 걷기유형에서는 유의한 차이를 보이지 않았다. 반면 걷기속도와 유형간의 상호작용효과는 유 의하였다 $(\mathrm{p}=.008)$. 사후비교 결과 지방산화율은 저속걷 기, 중속걷기, 고속걷기 순으로 낮아지는 경향을 보였다. 또한 지방산화율은 저속걷기와 중속걷기에서 일반걷기 와 모래주머니차고 걷기가 파워걷기와 덤벨들고 걷기보 다 높았고, 고속걷기에서는 모래주머니차고 걷기가 일 반걷기, 파워걷기 및 덤벨들고 걷기보다 높게 나타났다.

지방연소량은 걷기속도에 따라 유의한 차이가 나타 났으나 $(\mathrm{p}=.007)$ 걷기유형에서는 유의한 차이를 보이지 않았다. 걷기속도와 유형간의 상호작용효과도 유의성 이 나타나지 않았다. 걷기속도에 따른 사후비교 결과 지방연소량은 덤벨들고 걷기와 모래주머니차고 걷기에 서 저속걷기보다는 중속걷기와 고속걷기에서 높은 경 향을 보였다.

\section{논의}

이 연구의 결과 산소섭취량은 저속보다는 중속이, 중 속보다는 고속걷기에서 높게 나타나 보행속도가 빨라질 수록 산소섭취량이 증가되었는데, 대부분의 생리학적

\begin{tabular}{|c|c|c|c|c|c|c|c|c|}
\hline & Speed & $\begin{array}{l}\text { General } \\
\text { walking }(1)\end{array}$ & $\begin{array}{l}\text { Power } \\
\text { walking }(2)\end{array}$ & $\begin{array}{l}\text { Dumbbell } \\
\text { walking } 3\end{array}$ & $\begin{array}{l}\text { Sand } \\
\text { walking (4) }\end{array}$ & & $\boldsymbol{F}$ & Contrast \\
\hline \multirow{4}{*}{$\begin{array}{l}\mathrm{VO}_{2} \\
(\mathrm{ml} / \mathrm{kg} / \\
\mathrm{min})\end{array}$} & $\operatorname{low}(\mathrm{A}$ & $16.4 \pm 2.2$ & $17.9 \pm 2.1$ & $17.9 \pm 2.5$ & $17.6 \pm 2.6$ & Speed(S) & $227.551^{* * *}$ & ns \\
\hline & middle B & $20.4 \pm 2.7$ & $21.5 \pm 2.0$ & $21.9 \pm 3.2$ & $21.9 \pm 3.4$ & Type(T) & 1.413 & (1) $<$ (2)(3)(4) \\
\hline & high(C) & $26.6 \pm 4.0$ & $26.6 \pm 2.4$ & $27.5 \pm 3.3$ & $27.8 \pm 4.0$ & $(\mathrm{~S} \times \mathrm{T})$ & $2.290^{*}$ & (1) (2) $<$ (3) (4) \\
\hline & contrast & (A) $<$ (B) $<$ (C) & (A) $<$ (B) $<$ (C) & (A) $<$ (B) $<$ C & (A) $<$ (B) $<$ (C) & & & \\
\hline \multirow{4}{*}{$\begin{array}{l}\text { Fat } \\
\text { oxidation } \\
\text { rate } \\
(\%)\end{array}$} & $\operatorname{low} \AA$ & $37.4 \pm 13.6$ & 31.3. \pm 10.8 & $28.3 \pm 14.5$ & $34.6 \pm 15.2$ & Speed(S) & $53.986^{* * *}$ & (2) (3) $<$ (1) (4) \\
\hline & middle B & $33.1 \pm 11.2$ & $26.9 \pm 10.2$ & $28.7 \pm 13.6$ & $32.1 \pm 13.9$ & Type(T) & .329 & (2) (3) $<$ (1) (4) \\
\hline & high(C) & $21.3 \pm 14.5$ & $20.7 \pm 10.9$ & $21.9 \pm 10.5$ & $23.9 \pm 14.6$ & $(\mathrm{~S} \times \mathrm{T})$ & $3.314^{* *}$ & (1) (2) (3) $<$ (4) \\
\hline & contrast & (A) $>$ (B) $>$ (C) & (A) $>$ (B) $>$ (C) & (A) $>$ (B) $>$ (C) & (A) $>$ (B) $>$ (C) & & & \\
\hline \multirow{4}{*}{$\begin{array}{l}\text { Fat } \\
\text { oxidation } \\
\text { (kcal/min) }\end{array}$} & $\operatorname{low}(A)$ & $3.6 \pm 1.3$ & 3.3. \pm 1.1 & $3.0 \pm 1.4$ & $3.5 \pm 1.6$ & Speed(S) & $6.550^{* *}$ & ns \\
\hline & middle B & $3.5 \pm 1.4$ & $3.5 \pm 1.3$ & $3.7 \pm 1.6$ & $4.1 \pm 1.8$ & Type(T) & .215 & ns \\
\hline & high(C) & $3.4 \pm 2.3$ & $3.3 \pm 1.7$ & $3.6 \pm 1.8$ & $4.1 \pm 2.6$ & $(\mathrm{~S} \times \mathrm{T})$ & 1.107 & ns \\
\hline & contrast & (A) $=B=(C)$ & $(A)=B=C$ & (A) $<$ (B) $=$ C & (A) $<$ (B) $=$ (C) & & & \\
\hline
\end{tabular}


인 변인은 저속에서 감소하고 고속에서 증가하는 패턴 을 보인다는 견해와 일치하였다.[25]. 그에 반해 걷기 운동 유형별 각각의 산소섭취량은 저속의 경우 운동유 형 간에 비슷하였지만, 중속에서는 일반걷기보다 파워 걷기, 덤벨들고 걷기 및 모래주머니차고 걷기에서 높았 고, 고속에서는 일반걷기와 파워걷기보다 덤벨들고 걷 기와 모래주머니차고 걷기에서 높게 나타나 산소섭취 량은 걷기유형과 보행속도에 따라서 다르게 나타나는 경향을 보였다. 걷기운동시 보행 형태에 따라서 에너지 의 효율성이 달랐고 $[26,27]$, 중속과 고속걷기에서 파 워보행이 일반보행보다 산소소비량이 높았고[28], 몸 통, 손목, 발목에 각각 중량부하를 주어 걷기운동을 실 시하였을 때 산소섭취량이 높았으며 [14], 중량부하를 몸통 중심에서 벗어나게 부착할수록 산소소비량이 증 가되었다[29]. 이들 주장은 이 연구의 결과와 부합된다 고 보여 진다. 그렇지만 이 연구에서 저속의 경우에는 걷기유형에 관계없이 산소섭취량이 비슷하였으므로 이 들 주장에는 보행속도가 고려되어야 할 필요성을 시사 하였다. 중량부하 후 걷기운동을 실시할 때 운동부하량 의 영향을 받는 골격근에 혈류량이 증가하여 1 회박출 량이 커지고 동시에 혈류속도와 혈류량이 증가되어 중 량부하 후 걷기운동을 할 때 산소섭취량의 증가를 기대 할 수 있다고 하였는데[30], 이는 이 연구에서 중량부 하 조건에서 산소섭취량이 높게 나타난 것을 어느 정도 설명하고 있다고 보여진다.

지방산화율은 저속, 중속, 고속걷기 순으로 낮아져 운동강도가 높아질수록 지방산화가 낮아진다는의 연구 와 일치하였으며[31], 보행속도에 따라 호흡교환율이 유의한 차이를 보인다는 주장에 동의되었다[32]. 반면 에 운동유형별 각각의 지방산화율은 저속과 중속의 경 우 일반걷기와 모래주머니차고 걷기에서 높게 나타났고, 고속걷기에서는 모래주머니차고 걷기가 다른 3 가지 유 형보다 높게 나타나 지방산화율은 걷기유형과 보행속도 에 따라서 다른 경향을 보였다. 걷기유형에 따라서 호흡 교환율이 비슷하였다[33]. 또한 일반걷기보다 파워걷 기에서 호흡교환율이 높게 나타났고[26], 중속에서는 걷기유형 별로 차이가 없었지만 고속 조건에서의 호흡 교율율은 파워걷기에서 높게 나타나 부분적으로 이 연 구와 비슷한 양상을 보였다[28]. 일반걷기보다 $1.36 \mathrm{~kg}$ 의 손과 발목 중량부하 조건의 걷기운동에서 호흡교환 율이 높았다[34]. 이 연구에서는 이와 달리 저속과 중
속에서 일반걷기와 모래주머니차고 걷기 조건에서 비슷 하였고 고속에서는 선행연구와는 반대로 다른 모든 조 건의 걷기보다 모래주머니차고 걷기에서 지방연소율이 높게 나타났다. 이러한 결과는 매우 흥미 있는 발견이 라고 생각된다. 몇몇 선행연구에서는 보행속도가 빠를 수록 운동의 효과가 높다는 견해[18]가 있지만, $6 \mathrm{~km} / \mathrm{h}$ 이하의 속도에서는 효과가 아주 작으며 [15], 6 7km/ $\mathrm{h}$ 의 보행속도에서 가장 높았다는 주장이 있다[11]. 이 연구에서 고속조건의 보행속도는 약 $6 \mathrm{~km} / \mathrm{h}$ 정도인데, 이는 약 $1.7 \mathrm{~m} / \mathrm{sec}$ 에 해당하는 속도로서 일반적으로 빠 른 걷기에 해당된다. 따라서 이 연구의 범위 내에서 본 다면 빠른 걷기운동에서는 손보다는 발목에 중량부하를 주는 것이 운동효과가 높다는데[14] 동의되며 지방산 화에 더 효과적이라고 해석될 수 있기 때문이다. 왜 이 러한 결과가 나타났는지에 대한 기전은 이 연구에서 밝 힐 수 없지만 보행속도와 걷기유형에 따라 보행의 임계 점이 다를 수 있기 때문이 아닌가 예측되지만[26] 이를 규명하기 위해서는 후속연구가 필요할 것으로 생각된다.

지방연소량은 일반걷기와 파워걷기의 경우 보행속 도와 관계없이 거의 비슷한 양상을 보였으나, 덤벨들고 걷기와 모래주머니차고 걷기는 저속보다 중속과 고속 에서 높게 나타나는 경향을 보였다. 일반적으로 에너지 소비는 운동강도가 낮으면 지방동원율이 높고, 단위 시 간당 절대적인 열량소비량은 적다. 반대로 운동강도가 높으면 절대적인 에너지소비량은 증가되지만, 전체 에 너지소비량에서 상대적인 지방연소비율은 감소하게 된 다[30]. 따라서 이 연구에서 본다면 일반걷기와 파워걷 기의 경우에는 이러한 논리가 성립되는 것으로 보인다. 반면에 이 연구의 결과는 발목에 각각 중량부하를 주어 걷기운동을 실시하였을 때 에너지소비량이 발목조건에 서 가장 높게 나타났다는 연구[14]와 6 $7 \mathrm{~km} / \mathrm{h}$ 의 보 행속도에서 네 가지 걷기유형 중 모래주머니차고 걷기 에서 에너지소비량이 가장 높았다[11]는 연구와 비슷 하였다. 이 또한 이 연구에서 발견되는 흥미 있는 결과 라고 보여진다. 하지에 중량부하물을 부착하였을 때, 스 트라이드(stride), 무릎관절 각도, 동원 근육형태, 정적 근수축 형태 등이 변화되기 때문에 에너지소비가 커진 다고 하였는데[35], 이 연구의 범위 내에서 본다면 하 지의 중량부하 걷기는 다른 걷기유형보다 지방산화량을 높인다는 장점을 확인할 수 있었다. 그러나 이러한 주장 을 단언할 수는 없다. 왜냐 하면, 이 연구는 사례수가 적 
어 연구의 결과를 일반화시키는 데에는 다소 무리가 있 을 것으로 생각된다. 따라서 이를 명확하게 규명하기 위 해서는 후속연구가 필요할 것으로 생각된다.

\section{결론}

이 연구는 일반걷기, 파워걷기, 덤벨들고 걷기, 모 래주머니차고 걷기의 4 가지 운동유형과 저속걷기 $(40 \% \mathrm{VT})$, 중속걷기 $(50 \% \mathrm{VT})$, 고속걷기 $(60 \% \mathrm{VT})$ 의 세 가지 보행속도 수준에서 트레드밀 걷기운동을 실시하였 을 때, 산소섭취량, 지방연소율 및 지방연소량의 차이 를 알아보고자 10 명의 남자 대학생을 대상으로 연구를 수행한 결과, 산소소비량은 저속을 제외한 중속과 고속 걷기 조건의 경우 덤벨들고 걷기와 모래주머니차고 걷 기 유형에서 높게 나타났다. 지방산화율은 저속과 중속 의 경우 일반걷기와 모래주머니차고 걷기에서 높았고, 고속에서는 모래주머니차고 걷기에서 가장 두드러지게 높았다. 따라서 덤벨들고 걷기와 모래주머니차고 걷기 는 일반걷기보다 산소섭취량을 높이고, 일반걷기와 모 래주머니차고 걷기의 경우에는 지방산화율 높이는데 이 점이 있다고 보여진다. 특히 지방연소량을 고려할 때, 모든 속도 조건에서 모래주머니차고 걷기는 체중감량에 효용성이 있을 것으로 사료되며, 추후 이를 규명할 필요 가 있다고 제안한다.

\section{Acknowledgments}

이 논문은 김혜영의 석사 학위 논문을 수정 보완한 것임.

\section{Conflicts of Interest}

The authors declare no conflict of interest.

\section{References}

1. Park DS, Nam HS, Kim DH, Her JG, Woo JH. The Comparison of Exercise Intensity between Power Walking and Running. Korean J Sports Med. 2008; 26(2):175-179.

2. Hamila A, Younes M, Cottin F, et al. Effects of walking exercises on body composition, heart rate variability, and perceptual responses in overweight and obese adolescents. Science \& Sports. 2018; 33(5) 191-202.

3. Rontoyannis GP. Physical activity and hypertension: an overview, 5th International Conference on Nutrition and Fitness. Athens. 2004; 94, 120-128.

4. Kim YC, Kim YS, Yang JO, Lee BJ, Lee JS. Effects of aerobic and combined exercise on body composition and blood lipid in the middle-aged women. J Korean Data Inf Sci Soc. 2013; 24(6):1241-1251.

5. Kwon YG, Lee SI, Baek WS, Song MS, Park CY, Jang YW. The Effect of Rope - Jumping Exercise on Body Fat\% , VO2max and Serum Lipids Level in Obese Students in the Long Term. Journal of Sport and Leisure Studies. 2001; 15:425-436.

6. Lee HK. Physiological Responses according to Walking with Nordic Poles or Hand Weights on Treadmill. Asian J Kinesiol. 2009; 11(2):9-17.

7. Greiwe JS, Kohrt WM. Energy expenditure during walking and jogging. Sports Med Phys Fitness. 2000; 40(4):297302.

8. Dala U, Erdoganb T, Resitoglua B, Beydagia H. Determination of preferred walking speed on treadmill may lead to high oxygen cost on treadmill walking. Gait \& Posture. 2010; 31(3):366-369.

9. Schiffer T, Knicker A, Hoffman U, Harwig B, Hollmann W, Strüder HK. Physiological responses to nordic walking, walking and jogging. Eur J Appl Physiol. 2008; 98(1):5661.

10. Gi SJ, Chae WS, Kang NJ, Jang JI, Yoon CJ. The Comparative Analysis of EMG Activities on the Lower Limb Muscles during Power Walking and Normal Walking. Korean J Sport Biomech. 2008; 18(4):125-133.

11. Lee HK. The Study of HR and Energy Expenditure Change according to Walking Types. The Korea Contents Association proceedings. 2009; 7(1):405-409.

12. Pellegrini B, Alexandre L, Zoppirolliab C, et al. Mechanical energy patterns in nordic walking: comparisons with conventional walking. Gait \& Posture, 2017; 51:234-238.

13. Tschentscher M, Niederseer D, Niebauer J. Health Benefits of Nordic Walking: A Systematic Review. Am J Prev Med. 2013; 44(1), 76-84. 
14. Yang JS. Physiological responses to walking exercise with added weight at different locations in normal subjects. Korean J Phys Educ. 1996; 35(1):1130-1143.

15. Jeong IG, Yoon JH, Kim JO, Kim OP, Oh MJ, Seo TB. Effects of Leg-Weight Loading on Energy Expenditure and Heart Rate Response during Gradual Speed Treadmill Walking Exercise. Korean J Sports Med. 2003; 21(2):184 191.

16. Kim RB, Cho JH. The Effect of Weight Loading on Lower Extremity During Walking, Journal of Sport and Leisure Studies. 2011; 46(2):1161-1170.

17. Kang DH. Effects of dumbbell weight difference on heart rate and energy expenditure during walking. Phys Act Nutr. 2001; 5(2), 71-80.

18. Shin YA, Kim JH, Choi EH, Hong AR. The Comparative Analysis of Energy Expenditure, Muscle Activity and Fatigue on Gait Speed and Shoes Type. Korean Soc Sports Sci. 2012; 21(1):749-759.

19. Lee H. Effect of 12 Weeks of Rope-Jumping Training on Body Composition, Cardiovascular Disease Risk Factor and Insulin Resistance in Obese Middle-Aged Women. Korean J Growth Dev. 2001; 19(1), 25-30.

20. ACSM. ACSM's Guidelines for exercise testing and prescription. Philadelphia. Williams and Wilkins. 2006.

21. Park DH, Kim KH. The Use of Individual Anaerobic Threshold (IAT) for the Measurement of Blood Lipid and Lipoprotein As A Criterion of Exercise Intensity. The Korean Journal of Physical Education. 2001; 40(4):929-942.

22. Wasserman K, Hansen JE, Sue DY, Whipp BJ, Casaburi R. Principles of exercise testing and interpretation. Philadelphia : Lea \& Febinger. 1994; 64-65.

23. Ferrannini E. The theoretical basis of indirect calorimetry: A review. Metabolism. 1988; 37:287-301.

24. Rrayn KN. Calculation of substrate oxidation rates in vivo from gaseous exchange. J Appl Physiol. 1983; 98:628634.

25. Fukuchi CA, Fukuchi RK, Duarte M. Effects of walking speed on gait biomechanics in healthy participants: a systematic review and meta-analysis. Systematic Reviews. 2019; 8:153-164.

26. Jung HR, Ku HJ, Lee DT. Efficiency of Energy Cost during Walking According to Various Walking Patterns. Journal of Coaching Development. 2005; 7(3):143-150.

27. de David AC. Effects of changing speed on knee and ankle joint load during walking and running. J Sports Sci. 2015; 33(4):391-397.

28. Cha SH, Ji YS, Jeon, YK, Lee DB. Change of Cardiovascular Function to Walking Type. Journal of Wellness. 2010; 5(1):49-59.

29. Jones BH, Toner MM, Daniels WL, Knapik JJ. The energy cost and heart rate response of trained and untrained subjects walking and running in shoes and boots. Ergonomics. 1984; 27(8):895-902.

30. Shoemaker JK, Phillips SM, Green HJ, Hughson RL. Faster femoral artery blood velocity kinetics at the onset of exercise following short-term training. Cardiovasc Res. 1996; 31(2):278-286.

31. Achten J, Jeukendrup AE. Optimizing fat oxidation through exercise through exercise and diet. Nutrition. 2004; 20:716-727.

32. Lee HL. The effect of artificial change of velocity in walking exercise on energy consumption, oxygen consumption, blood pressure, heart rate, awareness of exercise and respiratory exchange ratio. Kun-kook University, Dissertation of Master's Degree. 2015; 45-48.

33. Yu YJ, Shin YA. The Response of Energy Expenditure Muscle Activity and Fatigue on Walking Type. Journal of Sport and Leisure Studies. 2008; 32:767-777.

34. Venables MC, Achten J, Ring C, Jeukendrup AE. Fat oxidation during exercise has stringer links to physical activity and VO2max than body fat. Med Sci Sports Exerc. 2003; 35:525-530.

35. Martin PE. Mechanical and physiological responses to lower extremity loading running. Med Sci Sports Exerc. $1985 ; 17(4): 427-433$. 